Research Article

\title{
Research on Bridge Structure Reliability Evaluation due to Vessels Collison Based on a Statistical Moment Method
}

\author{
Tao Fu (iD, Yang Liu, and Zhixin Zhu \\ School of Transportation Engineering, Shandong Jianzhu University, Jinan, China \\ Correspondence should be addressed to Tao Fu; greenvillage_17@163.com
}

Received 1 July 2021; Accepted 5 November 2021; Published 23 November 2021

Academic Editor: Abílio De Jesus

Copyright $\odot 2021$ Tao Fu et al. This is an open access article distributed under the Creative Commons Attribution License, which permits unrestricted use, distribution, and reproduction in any medium, provided the original work is properly cited.

\begin{abstract}
Damage to bridge structures caused by vessel collision is a risk for bridges crossing water traffic routes. Therefore, safety around vessel collision of existing and planned bridges is one of the key technical problems that must be solved by engineering technicians and bridge managers. In the evaluation of the reliability of the bridge structure, the two aspects of vessel-bridge collision force and structural resistance need to be considered. As there are many influencing parameters, the performance function is difficult to express by explicit function. This paper combines the moment method theory of structural reliability with finite element analysis and proposes a statistical moment method based on finite element analysis for the calculation of vessel-bridge collision reliability, which solves the structural reliability problem with a nonlinear implicit performance function. According to the probability model based on current velocity, vessel velocity, and vessel collision tonnage, the estimate points in the standard normal space are converted into estimate points in the original state space through the Rosenblatt reverse transform. According to the estimate points in the original state space and the simplified dynamic load model of vessel-bridge collision, the sample time-history curve of random vessel-bridge collision force is generated, the dynamic response of the bridge structure and the structural resistance of the bridge are calculated by establishing a finite element model, and the failure probability and reliability index of the bridge structure is calculated according to the fourth-moment method. The statistical moment based on the finite element analysis is based on the finite element analysis and the moment method theory of structural reliability. The statistical moment of the limited performance function is calculated through a quite small amount of confirmatory finite element analysis, and the structural reliability index and failure probability are obtained. The method can be widely used in existing finite element analysis programs, greatly reducing the number of finite element analyses needed and improving the efficiency of structural reliability analysis.
\end{abstract}

\section{Introduction}

According to data [1], vessel-bridge collision accidents occur every year around the world and bridge structures are seriously damaged or even collapse, such as the Sunshine Bridge and Queen Isabella Bridge in the United States and the Tasman Bridge in Australia [2]. Therefore, vessel-bridge collision is a factor that cannot be ignored in bridge design, and it is necessary to calculate the reliability of the bridge structure when bridge-vessel collision occurs. For the calculation of the reliability of the bridge structure, it is usually necessary to consider two aspects: vessel-bridge collision force and structural resistance [3]. Because of its many influencing parameters, it is difficult to display the performance function. In response to this problem, this paper combines the moment method theory of structural reliability and finite element analysis, according to the probability model of each influencing factor that affects the failure probability, and the finite element-statistical moment method is used to solve the structural reliability problem with a nonlinear implicit performance function.

Since the 1960s, bridges around the world have collapsed or been seriously damaged by vessel collision. Vessel collision accidents not only cause huge economic losses and casualties but can also have negative political impacts and cause serious environmental losses. The safety assessment of vessel collision of existing and planned bridges is one of the key technical problems that must be solved carefully by engineering technicians and bridge managers.

Reliability analysis of bridge structures under vessel collision is an important aspect of vessel-bridge collision 
safety assessment. The calculation of vessel collision reliability of a bridge structure involves two aspects: vessel collision force and structural resistance. There are many influencing factors, and the performance function is difficult to express by explicit function. At present, the methods of structural reliability analysis mainly include the first-order second-moment central point method [4], JC method [5], Monte Carlo method [6], and so on. The traditional structural reliability methods need to expand the performance function. It usually requires complex partial derivative calculation to solve the checking point by iterative calculation, which is difficult to use for structural reliability analysis with implicit performance function. The Monte Carlo method has the disadvantages of requiring large amounts of calculation and being time-consuming.

The AASHTO vessel collision design guidelines of the United States [7] provide a method to determine the bridge collapse probability PC by using the ratio of the limit lateral resistance $\mathrm{H}$ of the pier to the vessel collision force $P$, as shown in Figure 1. In addition, Proske and Curbach [8], Manuel et al. [9], Geng [10], Consolazio et al. [11], and other scholars used the first-order second-moment method, Latin hypercube sampling Monte Carlo method, and Markov chain Monte Carlo method to study the vessel collision reliability of bridge structures, mainly using Monte Carlo simulation based on deterministic finite element analysis, which requires large amounts of calculation and is time-consuming. In this paper, the vessel collision reliability of a bridge structure is analyzed by combining the structural reliability moment method theory and finite element analysis.

\section{Limit State Performance Function of Vessel- Bridge Collision}

\subsection{Performance Function of Components}

\subsubsection{Pile-Column Pier}

(1) Failure Mode of Pier Column. Under the action of vessel collision, the bridge pier column mainly suffers from bending failure or shear failure. The dynamic response of the bridge structure under vessel collision is a function of the three factors of vessel collision angle, vessel collision velocity, and vessel collision tonnage [12]; therefore, we consider the following:

When the pier column undergoes shear failure, the limit state performance function of the bridge pier column can be expressed as

$$
G(X)=V_{R(\text { Column })}-V_{S(\text { Column })}(V, \text { DWT }, \theta) .
$$

When the pier column undergoes bending failure, the limit state performance function of the bridge pier column can be expressed as

$$
G(X)=\theta_{R(\text { Column })}-\theta_{S(\text { Column })}(V, \text { DWT }, \theta) .
$$

In the above two formulas, $V$ represents the vessel collision velocity, DWT represents the vessel collision deadweight tonnage, and $\theta$ represents the vessel collision angle.

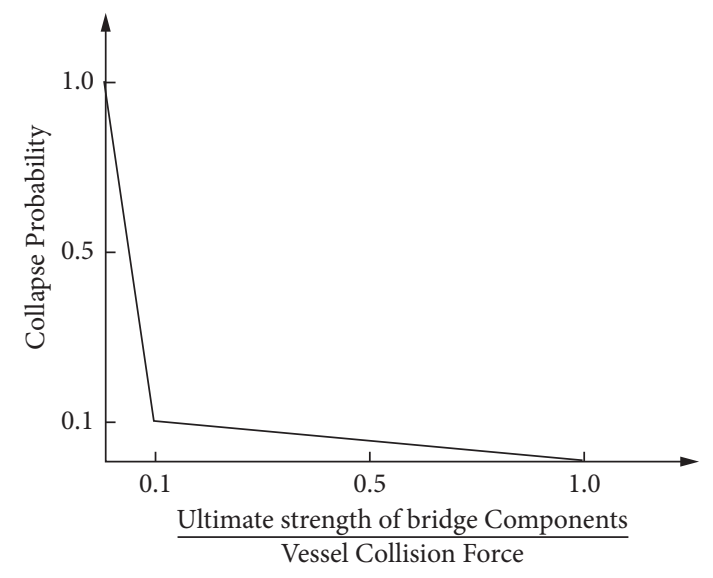

Figure 1: Distribution of collapse probability (AASHTO 2009).

(2) Failure Mode of Pile Group Foundation. For pile group foundations, according to the deformation failure criterion, in order to ensure that the pile group foundation is not destroyed, the rotation $\theta_{S(\text { Pile })}$ and limited values of component rotation $\theta_{R \text { (Pile) }}$ of the most dangerous pile of the pile group foundation under the vessel collision need to meet the following requirements [13]:

$$
\theta_{S(\text { Pile })}<\theta_{R(\text { Pile })}
$$

Thus, the limit state performance function of the bridge pier column can be expressed as

$$
G(X)=\theta_{S(\text { Pile })}-\theta_{S(\text { Pile })}(V, \text { DWT, } \theta)
$$

For a single pile-column pier system composed of pile group, pile caps, and piers (or tower columns), the failure of any one part will lead to the failure of the entire pier system. Therefore, the entire pier system forms a series system; then the limit state performance function of a single pile-column pier under vessel collision can be expressed as

$$
\begin{aligned}
& g=\min \left\{\theta_{R(\text { Pile })}-\theta_{S(\text { Pile })}\right. \\
& \left.\min \left\{V_{R(\text { Column })}-V_{S(\text { Column })}, \theta_{R(\text { Column })}-\theta_{S(\text { Column })}\right\}\right\} .
\end{aligned}
$$

\subsubsection{Open-End Caisson Foundation (Sunk Shaft} Foundation). The open-end caisson foundation sustains stability damage under vessel collision, mainly in the form of overturning and sliding. Therefore, the damage index can be expressed by the antioverturning stability coefficient $K_{0}$ and the antisliding stability coefficient $K_{c}$.

When the open-end caisson foundation undergoes overturning failure, the corresponding limit state performance function can be expressed as

$$
G(X)=K_{0}-\left[K_{0}\right]
$$

When the open-end caisson foundation undergoes sliding failure, the corresponding limit state performance function can be expressed as 


$$
G(X)=K_{c}-\left[K_{c}\right]
$$

In the above two formulas, $\left[K_{0}\right]$ represents the permissible antioverturning stability coefficient, and $\left[K_{c}\right]$ represents the permissible antisliding stability coefficient.

Thus, the limit state performance function of the openend caisson foundation under the vessel collision can be expressed as

$$
G(X)=\min \left\{K_{0}-\left[K_{0}\right], K_{c}-\left[K_{c}\right]\right\} .
$$

The limit state performance function of pile-column pier and open-end caisson foundation is unclosed to basic random variables; that is, the performance function is implicit, and the performance function itself has nonlinear characteristics. Because the functional relation of the bridge structure's response to basic variables under vessel collision is relatively complicated, the function in the result is often difficult to express explicitly [14].

\subsection{Limit State Performance Function of Bridge Structure} System. When any pier in the bridge structure system reaches the corresponding performance level state, the entire bridge structure system is considered to have reached the corresponding performance level state [8]. Therefore, the entire bridge structure can be regarded as a series system, so the calculation of the failure probability of vessel-bridge collision can be simplified to the calculation of the failure probability of a series structure system.

If a bridge system has $\mathrm{k}$ piers, the failure probability of the entire bridge system under vessel collision force can be expressed as

$$
P_{F}=\operatorname{Prob}\left[\min \left[g_{1}, g_{2}, \ldots, g_{k}\right]>0\right] .
$$

Therefore, the limit state performance function of the entire bridge structure system under the action of vessel collision force can be expressed as the minimum value of all the bridge pier performance functions; that is,

$$
G(X)=\min \left[g_{1}, g_{2}, \ldots, g_{k}\right] .
$$

Through the performance function of the bridge structure system established above, the reliability of the vessel-bridge collision system of the bridge structure under the action of vessel collision can be solved.

Aiming at the problem of vessel-bridge collision reliability analysis and solving failure probability of implicit performance function, this paper proposes a statistical moment method for calculating failure probability of vesselbridge collision based on finite element analysis, which is especially suitable for addressing the problem that the performance function cannot be expressed explicitly.

\section{Probability Model of Random Factors in Vessel-Bridge Collision Performance Function}

This paper selects the main factors that have a greater impact on the failure probability of vessel-bridge collision, including vessel collision tonnage, collision velocity, and collision angle.
3.1. Probability Model of Vessel Tonnage. The determination of vessel collision tonnage firstly depends on the determination of the deadweight tonnage of each type of vessel. For each type of vessel, its deadweight tonnage is not a fixed value but is distributed within a certain range. There is no unified view on the probability distribution of each type of vessel tonnage interval. This paper uses an unknown distribution model to simulate the distribution of vessel collision tonnage. Since the statistical probability characteristics of vessels passing through the bridge area can be described by statistical moments (mean value, standard deviation, skewness, and kurtosis), the probability distribution can be described by the first four order moments of statistical variables.

The probability density function can be expressed as

$$
\begin{aligned}
& f(x)=\frac{\varphi(u)}{\sigma\left(a_{2}+2 a_{3} u+3 a_{4} u^{2}\right)}, \\
& \frac{x-\mu}{\sigma}=a_{1}+a_{2} u+a_{3} u^{2}+a_{4} u^{3} .
\end{aligned}
$$

The distribution function is

$$
F(x)=\Phi(u)
$$

Among them $\mu$ is the mean value of the statistical variable; $\sigma$ is the standard deviation of the statistical variable; and $a_{1}, a_{2}, a_{3}, a_{4}$ are all coefficients, which are obtained from the first four order moments of the statistical variable.

Using this method to describe the tonnage of navigable vessels and directly reflecting the statistical characteristics of random variables according to the first four order statistical moments of random variables is more accurate.

3.2. Probability Model of Collision Velocity. The collision velocity of a vessel is one of the important factors that affect the collision force of a vessel. Typical upward and downward navigation velocities of various representative vessels are obtained by investigating vessel flow [15]. The AASHTO [16] specification adopts the broken line form shown in Figure 2 for the distribution of vessel collision velocity.

There are two random variables affecting vessel collision velocity: $V_{T}, V_{\text {MIN }}$.

The navigation velocity of the vessel and the mean value of current velocity are all subject to normal distribution, so the vessel collision velocity also follows a certain state distribution. This paper uses normal distribution to describe its probability characteristics.

Under the condition of $x \leq x_{c}$ and $x>x_{L}$, the mean value and standard deviation of the collision velocity are consistent with the mean value and standard deviation of $V_{T}$ and $V_{\text {MIN }}$.

Under the condition of $x_{c}<x<x_{L}$, the average collision velocity can be calculated as follows: 


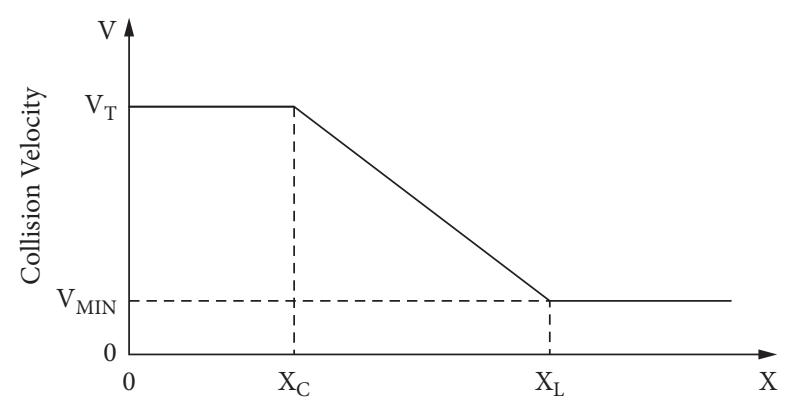

Figure 2: Distribution map of vessel collision velocity. $V$ : design collision velocity; $V_{T}$ : typical navigation velocity of vessels in channel; $V_{\text {MIN }}$ : minimum collision velocity (no less than annual mean value of current velocity); $x$ : distance between vessel and pier; $x_{c}$ : distance between vessel and channel edge; $x_{L}$ : distance of $3 \times$ LOA from the channel center line.

$$
\mu_{V}=\frac{x_{L} V_{T}-x_{c} V_{\mathrm{MIN}}-x\left(V_{T}-V_{\mathrm{MIN}}\right)}{x_{L}-x_{c}} .
$$

The standard deviation can be calculated as follows:

$$
\sigma_{V}=\frac{1}{x_{L}-x_{C}} \sqrt{\sigma_{V_{\mathrm{MIN}}}^{2}\left(x-x_{C}\right)^{2}+\sigma_{V_{T}}^{2}\left(x_{L}-x\right)^{2}} .
$$

3.3. Probability Model of Collision Angle. The angle of the vessel impacting a pier is not only related to wind direction, water flow, and other factors, but also related to the geometric shape of the bridge substructure and the relative channel position. Due to the lack of existing observation data on vessel yaw angle, the probability model of collision angle is described differently. This paper uses extreme I-type distribution to describe the probability model of collision angle, the mean value of collision angle on the straight route can be taken as $10-15^{\circ}$, and the standard deviation is $4-6^{\circ}$ on the nonstraight route, the mean value should consider the angle between the channel and the normal direction of the bridge axis [17].

The probability density function of extreme I-type distribution is

$$
f(x)=e^{-e^{-\alpha(x-u)}}
$$

In the formula,

$$
\left\{\begin{array}{l}
\alpha=\frac{\pi}{\sqrt{6} \cdot \sigma_{X}}=\frac{1.28255}{\sigma_{X}} \\
u=\mu_{X}-\frac{0.57722}{\alpha} .
\end{array}\right.
$$

\section{Calculation Model of Vessel-Bridge Collision Dynamic Response}

To simplify the analysis and calculation method, when analyzing the dynamic response of vessel-bridge collision, the vessel collision can be applied to the finite element model of bridge structure as a forced dynamic load [18], and the time-history response of the structure can be obtained by solving the basic dynamic equation. The analysis model is shown in Figure 3:

The vessel's forced dynamic load model adopts the modified half-wave sinusoidal load model. The time-history curve of vessel collision force is calculated according to the following formula:

$$
F(t)=\frac{I}{T} \frac{\pi}{k} T^{2}\left[\left(\frac{t}{T}-m\right)^{2}+n^{2}\right] \sin \left(\frac{\pi t}{T}\right),(0<t<T) .
$$

In the formula, $F(t)$ refers to the time course of impact force (MN); I refers to the momentum of vessels (MNS); $T$ refers to the duration of vessel collision (s); $t$ refers to the time (s); and $k, m$, and $n$ are dimensionless model parameters.

\section{Statistical Moment Method for Calculating Failure Probability of Vessel-Bridge Collision}

The probability distribution of the performance function is a function of random variables. The shape and position of the distribution curve of the probability density function of the performance function are closely related to the moment of the performance function [19]. The failure probability of the structure can be calculated by finding the relationship between the failure probability and the central moment of the performance function. Therefore, the first several order central moments of the performance function need to be solved.

5.1. Point Estimate of Statistical Moments of Performance Function. For the point estimate of performance function with multiple random variables, when calculating the moment of performance function $g(X)$, the performance function can be replaced by the following function formula:

$$
g^{*}(X)=\sum_{i=1}^{n}\left(g_{i}-g_{\mu}\right)+g_{\mu}
$$

Since $u_{i}$ is an independent random variable and $g_{i}$ is only a function of the random variable, $u_{i}$ is also independent, and the first four order statistical moments of $g_{i}$ can be calculated by the following formula:

$$
\begin{gathered}
\mu_{g}=\sum_{i=1}^{n}\left(\mu_{i}-g_{\mu}\right)+g_{\mu}, \\
\sigma_{g}^{2}=\sum_{i=1}^{n} \sigma_{i}^{2}, \\
\alpha_{3 g} \sigma_{g}^{3}=\sum_{i=1}^{n} \alpha_{3 i} \sigma_{i}^{3}, \\
\alpha_{4 g} \sigma_{g}^{4}=\sum_{i=1}^{n} \alpha_{4 i} \sigma_{i}^{4}+6 \sum_{i=1}^{n-1} \sum_{j>i}^{n} \sigma_{i}^{2} \sigma_{j}^{2} .
\end{gathered}
$$




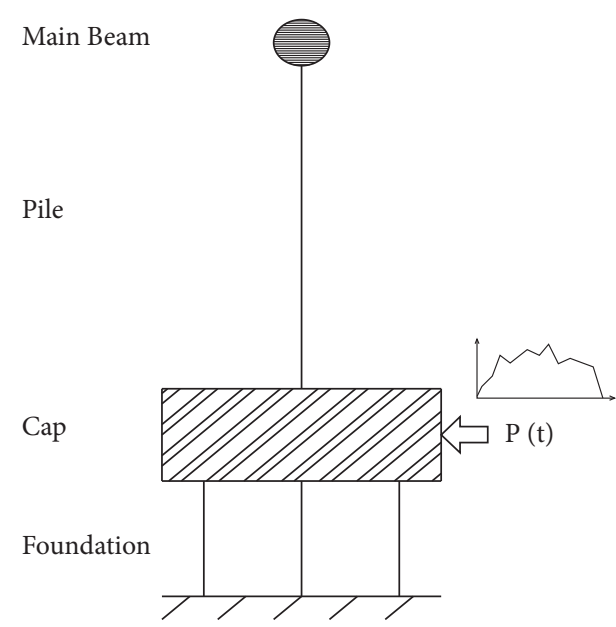

FIGURE 3: Forced vibration analysis model of vessel-bridge collision.

5.2. Fourth-Moment Reliability Index Based on Pearson System. For standardized random variable $Z_{s}$, the probability density function satisfies the following partial differential equation:

$$
\frac{1}{f} \frac{d f}{d Z_{s}}=-\frac{a Z_{s}+b}{c+b Z_{s}+d Z_{s}^{2}} .
$$

In the formula, respectively, $a, b, c$, and $d$ are

$$
\begin{aligned}
& a=10 \alpha_{4 G}-12 \alpha_{3 G}-18, \\
& b=\alpha_{3 G}\left(\alpha_{4 G}+3\right), \\
& c=4 \alpha_{4 G}-3 \alpha_{3 G}^{2}, \\
& d=2 \alpha_{4 G}-3 \alpha_{3 G}^{2}-6 .
\end{aligned}
$$

Therefore, the reliability index based on the fourth moment can be expressed as

$$
\beta_{4 M-P}=-\Phi^{-1}\left[\int_{-\infty}^{-\beta_{2 M}} f\left(z_{s}\right) \mathrm{d} z_{s}\right] .
$$

\section{Statistical Moment Method for Vessel-Bridge Collision Failure Probability Calculation Based on Finite Element Analysis}

For the nonlinear implicit performance function, the traditional reliability analysis method cannot be solved. In this paper, the structural reliability moment method is combined with the finite element method, and the finite element analysis method is used to calculate the dynamic response of the vessel collision and the performance index boundary value of the structure. Through the finite element calculation, the failure probability of the structure is obtained, which greatly improves the calculation efficiency of the failure probability analysis. The calculation process is shown in Figure 4 below.

The concrete ideas are as follows:

(1) In view of the factors affecting the failure probability of vessel-bridge collision, vessel tonnage, collision velocity, and collision angle, probability models are selected, respectively, and the limit state performance function of vessel-bridge collision is established according to the analysis model.

(2) According to the probability model of each influencing factor, the estimate points in the standard normal space are converted into estimate points in the original state space through the Rosenblatt reverse transform. According to the estimate points in the original state space and the simplified dynamic load model of vessel-bridge collision, the sample time-history curve of random vessel-bridge collision force can be generated.

(3) Establish the finite element model of bridge structure. According to the sample time-history curve of vessel collision force, the dynamic response of bridge under vessel collision is solved by finite element analysis.

(4) This paper considers that when the most unfavorable angle of pile top is greater than the limit angle, the bridge structure is destroyed. According to the actual reinforcement at the top of the pile foundation, the limit value of the performance index of the bridge structure, namely, the limit rotation angle, is calculated by finite element analysis.

(5) According to the obtained dynamic response of vessel collision and the performance index limit value of the bridge structure, the statistical moment of the limit state performance function of the bridge structure is calculated, and the corresponding failure probability of the bridge pier under the action of the sample time-history curve of the vessel collision force is calculated from the obtained statistical moment.

(6) Repeat steps (1)-(5) for different piers, and the corresponding failure probability of each bridge pier under the sample time-history curve of the vessel collision force is obtained.

\section{Engineering Application Examples}

7.1. Fundamental Data. The main bridge of a bridge is a three-span prestressed concrete continuous rigid frame system with a span of $55+100+55 \mathrm{~m}$ (Figure 5 ). The main girder is box-section beam, the section form is single box and single chamber, the left and right bridge are separated, the top width of box girder is $17.49 \mathrm{~m}$, and the bottom width is $9 \mathrm{~m}$. The lengthwise curve of the bottom of the box girder is a quadratic parabola, with a root beam height of $5.4 \mathrm{~m}$ and a mid-span beam height of $2.5 \mathrm{~m}$ (both referring to the outer edge of the lateral web plate). The main and auxiliary navigation standard of this bridge is grade $\mathrm{V}$, and the navigation clearance is as follows: the bottom width, top width, and net height of the main navigation hole are, respectively, $90 \mathrm{~m}, 80 \mathrm{~m}$, and $7 \mathrm{~m}$. The No. 0 platform is a gravity U-shaped platform, the No. 1 and No. 2 main piers are four-column piers (Figure 6), the top of the column and 


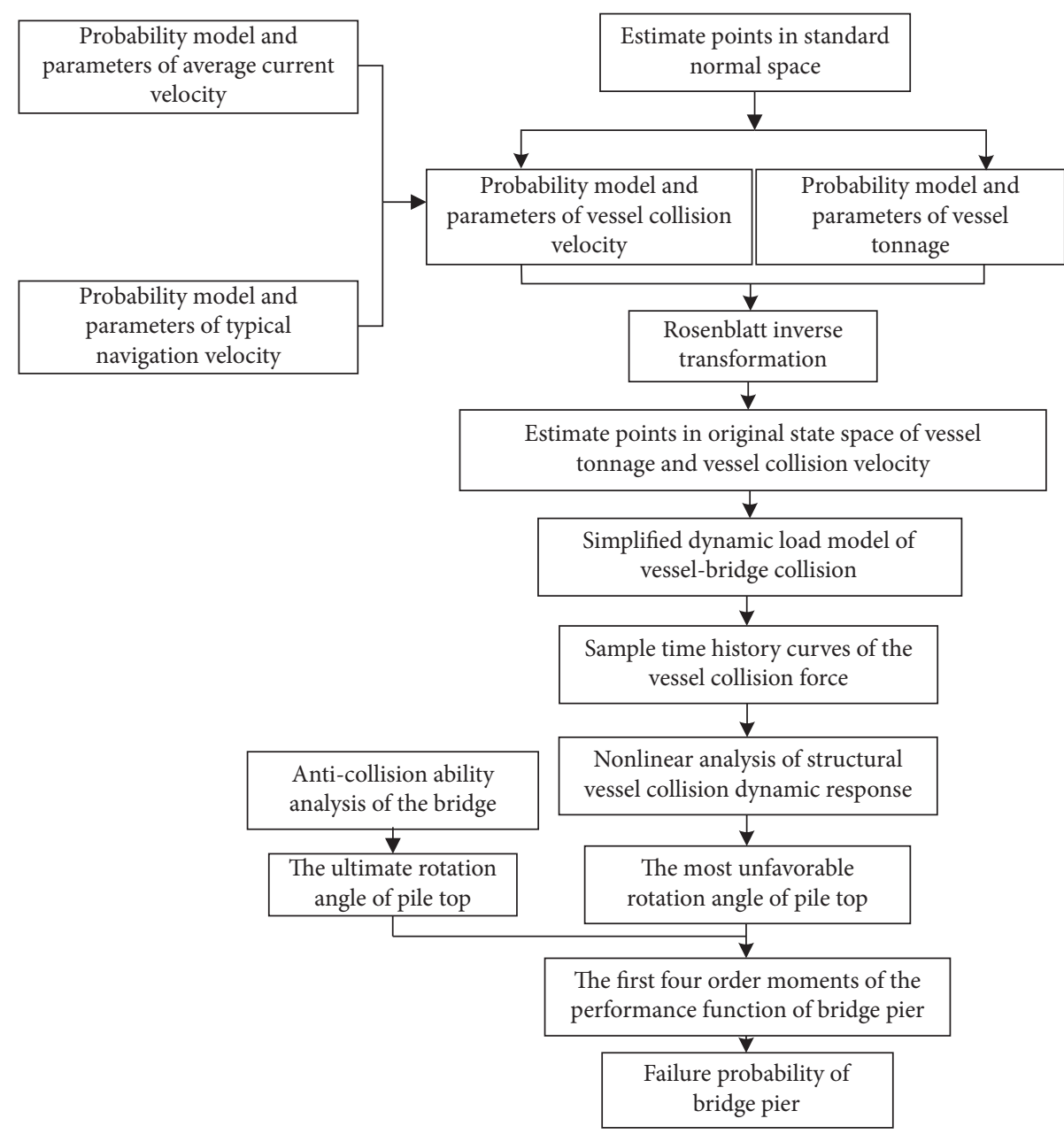

FIGURE 4: Basic process of vessel collision failure probability analysis for bridge structure.

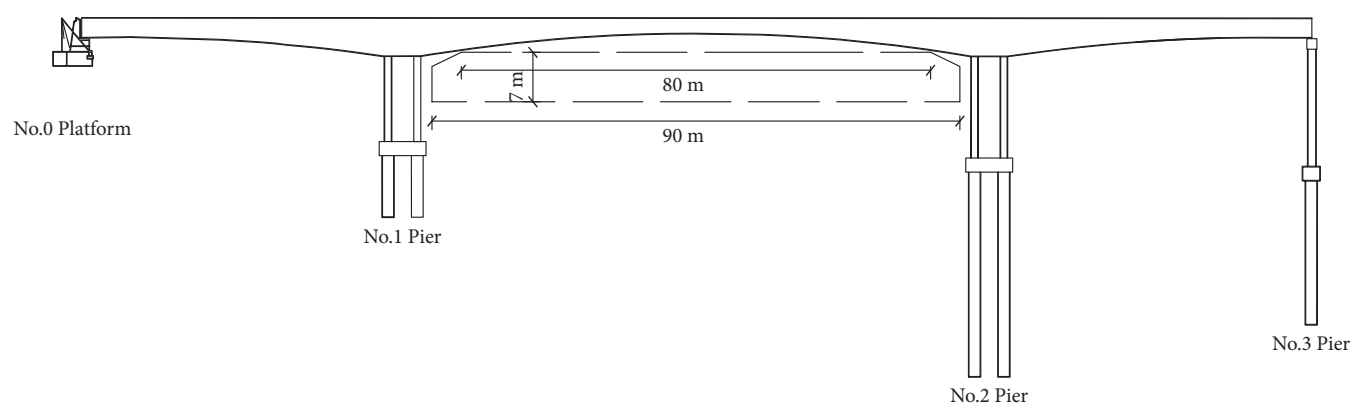

Figure 5: Layout of a bridge in Guangdong.

the box girder are rigid, and the foundation is rock-socketed pile; No. 3 transition pier is a single-row double-column pier, the foundation is rock-socketed pile, and each pier is connected by a tie beam.

7.2. The Finite Element Model of Bridge Structure. Midas/Civil was used for finite element modeling analysis. The main beam, pier, cover beam, tie beam, cap, and pile foundation were simulated by spatial beam element. According to the specific form, the bridge bearing is simulated by coupling the degree of freedom between the node on the pier or tower and the corresponding node on the main beam, and the bottom of the cap and pile foundation adopt a master-slave constraint; the main beam and the middle-pier are rigidly connected, the main beam and the side pier are elastically connected, and the pile foundation is embedded at 4 times the pile diameter below the scour line. The model takes the longitudinal direction as the $X$ axis, the transverse direction as the $Y$ axis, and the vertical direction as the $Z$ axis (Figure 7 ). The corresponding relationship between each component and the model is as follows: 


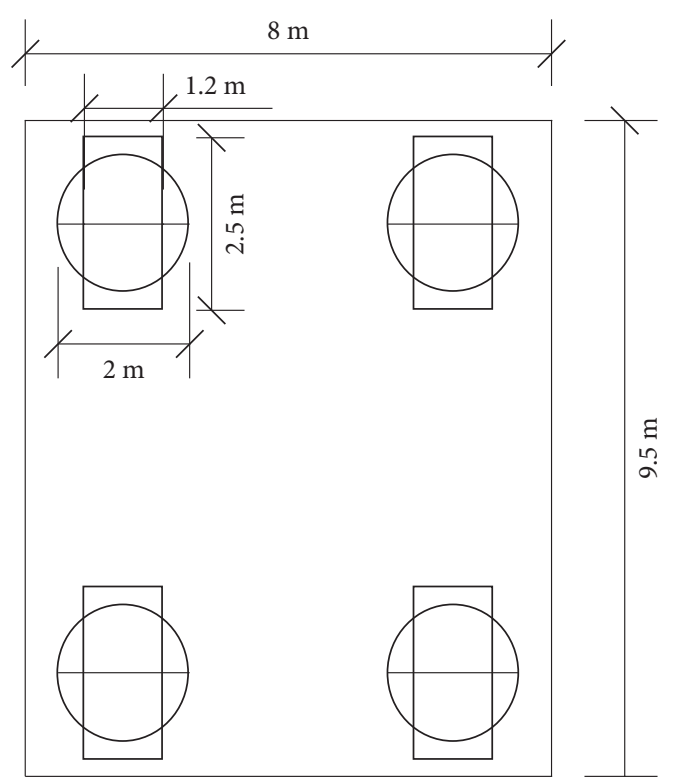

Figure 6: Pile foundation arrangement form of main bridge pier column.

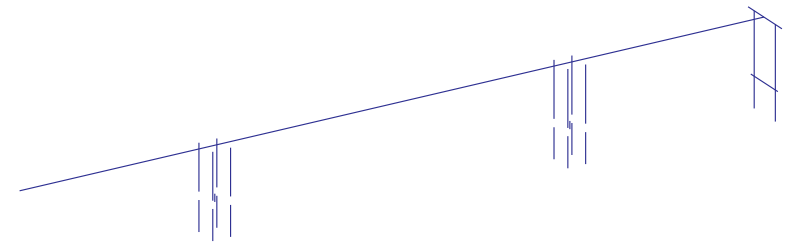

Figure 7: Dynamic finite element model of the bridge.

The material parameters of the bridge structure are shown in Table 1 (the plastic hinge is set at the top of the pile foundation, and the limit rotation angle is determined by the $M-\varphi$ curve according to the actual reinforcement of the section).

\subsection{The Sample Time-History Curve of the Vessel Collision Force}

7.3.1. Sample Value of Vessel Collision Velocity. In this paper, two random variables of collision tonnage and collision velocity are considered as influencing factors of vessel collision force. As shown in Figure 4, vessel collision velocity is determined by two random variables of typical navigation velocity and average current velocity. According to the actual hydrological situation of the bridge, the probability models and parameters of the two random variables of typical navigation velocity and average current velocity are shown in Table 2. According to the mean value and coefficient of variation of these two random factors, combined with the structural layout and navigation requirements of the bridge, the mean value of collision velocity is $3.47 \mathrm{~m} / \mathrm{s}$, and the coefficient of variation is 0.043 . According to the above theoretical analysis, this paper uses five-point estimation, and the estimation points in the standard normal space are shown in Table 3 . The collision velocity in this paper adopts the normal distribution. According to the estimation points in the standard normal space and the mean value and coefficient of variation of the collision velocity, five grades of collision velocity are obtained through the Rosenblatt inverse transform, which are, respectively, $3.044 \mathrm{~m} / \mathrm{s}, 3.268 \mathrm{~m} / \mathrm{s}, 3.470 \mathrm{~m} / \mathrm{s}, 3.672 \mathrm{~m} / \mathrm{s}$, and $3.896 \mathrm{~m} / \mathrm{s}$, and are used for the velocity value of the sample time-history curve of the vessel collision force.

7.3.2. Sample Value of Vessel Tonnage. According to the practical statistical analysis of vessel tonnage, the mean value of vessel tonnage is $4568 \mathrm{t}$, and the coefficient of variation is 0.9674 . Due to the large discreteness of vessel tonnage, the vessel tonnage in this paper adopts the unknown distribution probability function. According to the mean value and coefficient of variation of vessel tonnage, five grades of vessel tonnage are obtained by the Rosenblatt inverse transform, which are, respectively, $45.866 \mathrm{t}, 41.774 \mathrm{t}, 3431.070 \mathrm{t}, 10999.100 \mathrm{t}$, and $25376.200 \mathrm{t}$ and are used for the vessel tonnage value of the sample time-history curve of the vessel collision force.

\subsubsection{The Sample Time-History Curve of the Vessel Collision} Force. In this paper, the vessel tonnage adopts unknown distribution, and the impact velocity adopts normal distribution. The corresponding relationships of specific samples are shown in Table 4.

This paper adopts the modified half-wave sinusoidal load model. According to the collision tonnage and collision velocity under various working conditions, 10 sample timehistory curves of the vessel collision force are obtained. The sample time-history curves of vessel collision force under partial working conditions are shown in Figure 8.

7.4. Calculation of Bridge Failure Probability. Bridges are prone to bending failure at the top of pile foundation under vessel collision. When bending failure occurs at the top of the most unfavorable pile foundation, it is considered that the entire bridge system is damaged.

As shown in Figure 4, the failure probability of bridge pier is calculated by ultimate rotation angle of pile top and the most unfavorable rotation angle of pile top. In this instance, the ultimate rotation angle is calculated by the actual reinforcement at the pile top according to the $M-\Phi$ curve, and the most unfavorable rotation angle at the pile top is obtained by analyzing the finite element model. 10 different sample time-history curves of vessel collision force are applied to the bridge cap, elastic-plastic hinges are set on the top of the pile, and through nonlinear dynamic time-history analysis, the maximum rotation response of the plastic hinge zone at the top of the most unfavorable pile foundation of the main pier group pile foundation is shown in Table 5.

According to the actual reinforcement of the pile top, the ultimate rotation angle of the pile top of No. 1 pier is $2.432 \mathrm{E}$ 02 , and the ultimate rotation angle of the pile top of No. 2 pier is $2.475 \mathrm{E}-02$. According to the above theory, the failure probability of middle-pier calculated by the program is shown in Table 6. 
TABLE 1: Material parameters of the bridge structure.

\begin{tabular}{lccr}
\hline Component & Strength grade & Elastic modulus $\left(\mathrm{kN} / \mathrm{m}^{2}\right)$ & Density $\left(\mathrm{kN} / \mathrm{m}^{3}\right)$ \\
\hline Main beam & C50 & $3.45 \times 10^{7}$ & 25 \\
Pier column & C30 & $3.00 \times 10^{7}$ & 25 \\
Cover beam & C30 & $3.00 \times 10^{7}$ & 25 \\
Platform & C30 & $3.00 \times 10^{7}$ & 25 \\
Pile foundation & C30 & $3.00 \times 10^{7}$ & 25 \\
\hline
\end{tabular}

TABLE 2: Probability model and parameter value of random factors.

\begin{tabular}{lccc}
\hline Random factor & Probability model & Mean value & Coefficient of variation \\
\hline Typical navigation velocity & Normal distribution & $4 \mathrm{~m} / \mathrm{s}$ & 0.2 \\
Average current velocity & Normal distribution & $2.41 \mathrm{~m} / \mathrm{s}$ & 0.2 \\
\hline
\end{tabular}

TABLE 3: Estimation points in the standard normal space.

\begin{tabular}{lcccc}
\hline 1 & 2 & 3 & 4 & 5 \\
\hline-2.85697001 & -1.35562618 & 0 & 1.35562618 & 2.85697001 \\
\hline
\end{tabular}

TABLE 4: The correspondence between tonnage sample and collision velocity sample.

\begin{tabular}{lcc}
\hline Working condition & Collision tonnage $(\mathrm{t})$ & Collision velocity $(\mathrm{m} / \mathrm{s})$ \\
\hline 1 & 4568.000 & 3.470 \\
2 & 45.886 & 3.470 \\
3 & 41.774 & 3.470 \\
4 & 3431.070 & 3.470 \\
5 & 10999.100 & 3.470 \\
6 & 25376.200 & 3.470 \\
7 & 3431.070 & 3.044 \\
8 & 3431.070 & 3.268 \\
9 & 3431.070 & 3.672 \\
10 & 3431.070 & 3.896 \\
\hline
\end{tabular}

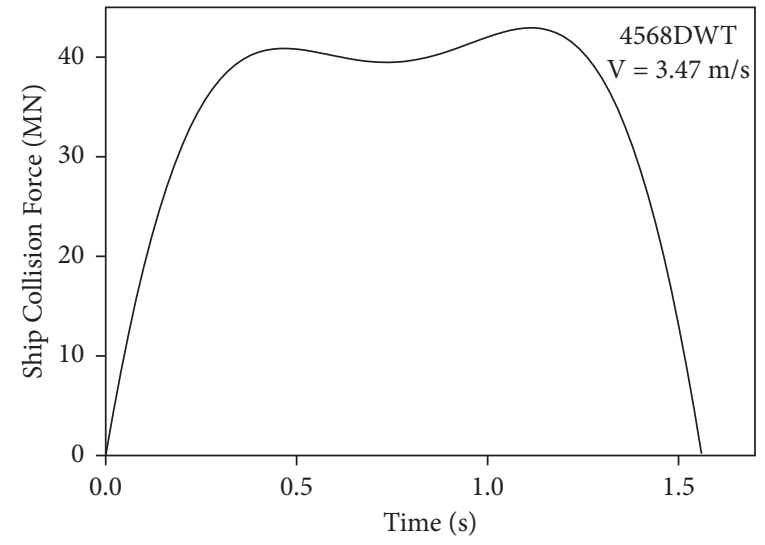

(a)

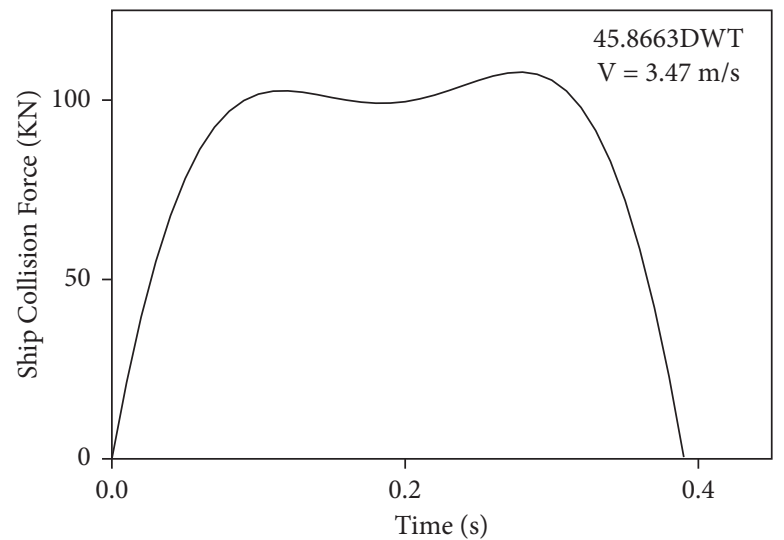

(b)

Figure 8: Continued. 


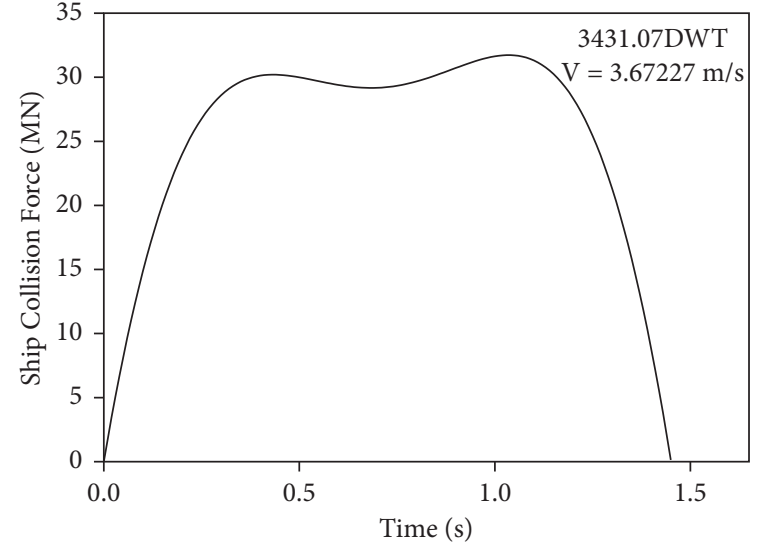

(c)

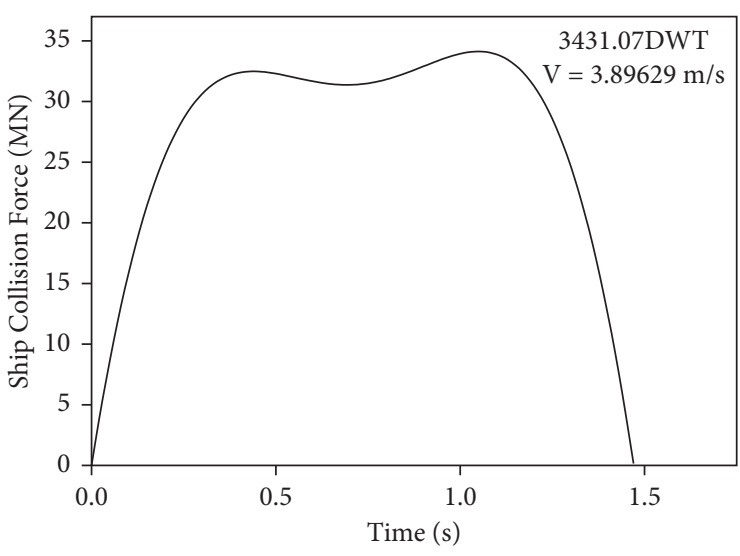

(d)

FIGURE 8: Sample time-history curves of the vessel collision force. (a) Under working condition 1. (b) Under working condition 2. (c) Under working condition 9. (d) Under working condition 10.

TABLE 5: Maximum rotation angle of plastic hinge zone at top of pile foundation.

\begin{tabular}{lcc}
\hline $\begin{array}{l}\text { Working } \\
\text { condition }\end{array}$ & $\begin{array}{c}\text { The maximum angle of } \\
\text { pile top of No. 1 pier }\end{array}$ & $\begin{array}{c}\text { The maximum angle of } \\
\text { pile top of No. 2 pier }\end{array}$ \\
\hline 1 & $2.386 \mathrm{E}-03$ & $1.513 \mathrm{E}-03$ \\
2 & $1.379 \mathrm{E}-03$ & $1.206 \mathrm{E}-03$ \\
3 & $1.031 \mathrm{E}-03$ & $4.800 \mathrm{E}-04$ \\
4 & $2.368 \mathrm{E}-03$ & $1.797 \mathrm{E}-03$ \\
5 & $5.002 \mathrm{E}-03$ & $4.796 \mathrm{E}-03$ \\
6 & $2.288 \mathrm{E}-02$ & $2.176 \mathrm{E}-02$ \\
7 & $1.556 \mathrm{E}-03$ & $1.480 \mathrm{E}-03$ \\
8 & $1.887 \mathrm{E}-03$ & $1.764 \mathrm{E}-03$ \\
9 & $2.269 \mathrm{E}-03$ & $1.755 \mathrm{E}-03$ \\
10 & $2.486 \mathrm{E}-03$ & $2.725 \mathrm{E}-03$ \\
\hline
\end{tabular}

TABLE 6: Failure probability of middle-pier.

\begin{tabular}{lcc}
\hline & No. 1 pier & No. 2 pier \\
\hline Failure probability & $2.190 \mathrm{E}-03$ & $2.510 \mathrm{E}-03$ \\
Reliability index & 2.849 & 2.806 \\
\hline
\end{tabular}

\section{Conclusions}

In this paper, a method and process of reliability analysis of bridge structure under vessel collision are established. In view of the implicit and nonlinear characteristics of the limit state performance function of the vessel-bridge collision and the limitations of the traditional reliability analysis method to solve the problem, a statistical moment method based on finite element analysis is proposed, which greatly improves the computational efficiency of structural failure probability with implicit performance function. The method is applied to the reliability analysis of vessel-bridge collision. The reliability analysis model and performance function of vesselbridge collision failure probability calculation are established, and the probability model of each influencing factor affecting the failure probability is established. Due to the characteristic of large discreteness of vessel tonnage in bridge areas, the unknown distribution model is used to simulate the distribution of vessel collision tonnage, and the first four order statistical moments of statistical variables are used to describe its probability distribution. The method established in this paper is used to analyze the reliability of vessel-bridge collision in practical bridge engineering, which provides a reference for the specific application of this method in practical engineering.

\section{Data Availability}

The underlying data used to support the findings of this study are included within the article.

\section{Conflicts of Interest}

The authors declare that they have no conflicts of interest.

\section{Acknowledgments}

This research has been supported by National Natural Science Funds, Grant no. 51408339, China, Natural Science Funds of Shandong Province, Bridge Structure Design Method Due to Vessels Collision Based on Life-cycle theory, and Postgraduate Education Quality Improvement Program Funds of Shandong Province, Grant no. SDYAL19110.

\section{References}

[1] D. Larsen, Vessel Collision with Bridges, IABSE Structural Engineering Documents, Zürich, Switzerland, 1993.

[2] M. J. Petersen, "Dynamics of ship collisions," Ocean Engineering, vol. 9, no. 4, pp. 295-329, 1982.

[3] J. H. Shao, R. D. Zhao, and B. Geng, "Probability analysis of vessel-bridge collapse based on reliability," in Proceedings of the Journal of Highway and Transportation Research and Development, Washington, DC, USA, January 2014.

[4] J. R. Zhang and Y. Liu, Structural Reliability Theory and its Application in Bridge Engineering, China Communications Press, Beijing, China, 2003.

[5] G. F. Zhao, Reliability of Engineering Structure, Water Resources and Electric Power Press, Beijing, China, 1984. 
[6] J. Li, Random Structural Systems, Science Press, Beijing, China, 1996.

[7] B. Aashto, Guide Specification and Commentary for Vessel Collision Design of Highway Bridges, American Association of State Highway and Transportation Officials, Washington, DC, USA, Second edition, 2009.

[8] D. Proske and M. Curbach, "Risk to historical bridges due to ship impact on German inland waterways," Reliability Engineering \& System Safety, vol. 90, pp. 261-270, 2005.

[9] L. Manuel, L. F. Kallivokas, E. B. Williamson, M. Bomba, and K. B. Berlin, "Probabilistic analysis of the frequency of bridge collapses due to vessel impact," Texas Dept. of Transportation, Austin. Research and Technology Implementation Office, Federal Highway Administration, Austin, TX, USA, 2006.

[10] B. Geng, Safety assessment of vessel-bridge collision, $\mathrm{PhD}$ Thesis, Tongji University, Shanghai, China, 2007.

[11] G. R. Consolazio, M. T. Davidson, and D. J. Getter, "Vessel crushing and structural collapse relationships for bridge design," research report, pp. 1-231, Dept. of Civil Engineering, University of Florida, Gainesville, FL, USA, 2010.

[12] J. J. Wang and B. Geng, Vessel-bridge Collision Probability Risk Assessment and Measures, China Communications Press, Beijing, China, 2010.

[13] X. L. Liu, Reliability Analysis of Vessel Collision on Pile Group Foundation, pp. 63-65, Urban Roads Bridges \& Flood Control, 2013.

[14] S. Haris and J. Amdahl, "Analysis of ship-ship collision damage accounting for bow and side deformation interaction," Marine Structures, vol. 32, pp. 18-48, 2013.

[15] L. T. Bu, A Probabilistic Simplified Method of Vessel Impact on Bridges, Tongji University, Shanghai, China, 2011.

[16] K. K. Peng, "Dynamic ship-bridge collision risk decision method based on time-dependent AASHTO model," Journal of The Institution of Engineers (India): Series A, vol. 102, no. 1, pp. 305-313, 2021.

[17] L. L. Wang, G. Y. Chen, and L. M. Yang, "Thesis of shock dynamics induced by vessel-bridge collision," Journal of Vibration and Shock, vol. 34, no. 3, 2015.

[18] Y. F. Mao, Experimental and Theoretical Study on Dynamic Response of Vessel-Bridge Collision, Nanjing University of Technology, Nanjing, China, 2016.

[19] D. Peng, Research on Vessel-Bridge Collision Simulation and Performance of New Bridge Protection Device, Beijing Jiaotong University, Beijing, China, 2018. 